\title{
Comparison of INNO-LIPA and TRUGENE Assays for Genotyping and Drug-Resistance Mutations in Chronic Hepatitis B Virus Infection
}

\author{
Miren Basaras $^{a} \quad$ Elisabete Arrese $^{a} \quad$ Sonia Blanco $^{b} \quad$ L. Sara Arroyo ${ }^{a} \quad$ Pablo Ruiz $^{b}$ \\ Ramón Cisterna ${ }^{a, c}$
}

${ }^{a}$ Department of Immunology, Microbiology and Parasitology, Medicine and Odontology Faculty, University of Basque Country UPV/EHU, Leioa-Bizkaia, ' Digestive Service and ${ }^{\mathrm{C} M i c r o b i o l o g y}$ and Infection Control Service, Basurto University Hospital, Bilbao-Bizkaia, Spain

\section{Key Words}

Hepatitis B virus genotype · Drug-resistance mutation ·

Line probe assay

\begin{abstract}
Objective: Hepatitis B virus (HBV) genotyping and detection of resistance to drugs have become essential in epidemiological and clinical diagnosis. Our main objective was to determine the prevalence of HBV genotypes and drug-resistance mutations in chronic asymptomatic carriers and chronic HBV sufferers comparing 2 detection assays. Methods: Serum samples from 28 chronic HBV patients and 22 chronic asymptomatic carriers were analyzed. For HBV genotyping, the INNO-LIPA and TRUGENE ${ }^{\text {TM }}$ HBV genotyping kits were evaluated. For drug-resistance mutations, INNOLIPA DR V2 and INNO-LIPA DR v3 prototype and the TRUGE$\mathrm{NE}^{\mathrm{TM}} \mathrm{HBV}$ genotyping kit were evaluated. Results: In HBV genotyping, concordant results were $98 \%$ and both assays were able to detect more than one genotype. Different genotypes were detected, the most prevalent being $D$ $(46 \%)$ and A (26\%). In relation to drug-resistance mutations, the sensitivity of the line probe assay was lower than TRUGENE because INNO-LIPA could not detect two mutations
\end{abstract}

(S202G and V214A). Conclusions: Both assays are easy and suitable for detecting HBV genotype and drug-resistance mutations and for routine laboratory use. However, TRUGENE presented better sensitivity in both analyses and it is possible to conduct both on the same sample. This assay is also able to detect primary and secondary mutations.

Copyright $\odot 2013$ S. Karger AG, Basel

\section{Introduction}

Hepatitis B virus (HBV) infection is a global health issue and a major cause of acute and chronic liver disease worldwide. More than 350-400 million people are infected with HBV [1], and they are at a very high risk for developing severe liver diseases including liver cirrhosis and hepatocellular carcinoma. Every year, approximately 1 million people die due to HBV infection; 33\% of these deaths are caused by hepatocellular carcinoma and the rest by the terminal complications of liver disease [2].

Genomic mutations presented during HBV reverse transcription could explain its genetic diversity and account for the 8 genetically distinct genotypes, designated A-H. These genotypes show distinctive geographical dis-

\section{KARGER}

E-Mail karger@karger.com

www.karger.com/int
(C) 2013 S. Karger AG, Basel

0300-5526/13/0563-0190\$38.00/0
Dr. Miren Basaras, Professor of Microbiology

Department of Immunology, Microbiology and Parasitology

Medicine and Odontology Faculty, University of Basque Country (UPV/EHU)

Sarriena auzoa, ES-48940, Leioa-Bizkaia (Spain)

E-Mail miren.basaras@ehu.es 
tribution across the entire world [3]. Moreover, the diversity of HBV genotypes may be related to the clinical patterns of infection, the development of cirrhosis and hepatocellular carcinoma and resistance to antiviral treatment [4].

Nowadays, there are several techniques to detect HBV genotypes: reverse hybridization [5], restriction fragment-length polymorphism [6], genotype-specific PCR assays [7], sequence analysis [8], microarray (DNAchip) [9] and fluorescence polarization assay [10]. However, a rapid and easy-to-use genotyping assay could become an essential and routinely used tool for disease management.

To date, prolonged therapy with nucleoside/tide analogs usually confers drug resistance because of the presence of mutations in the target gene [11,12]. These mutations should be detected using rapid and specific methods which allow the identification of all substitutions. These mutations can also appear in patients without any therapy regimen, indicating a natural pressure selection.

The objective of this study was to determine the prevalence of HBV genotypes and drug-resistance mutations in a group of chronic asymptomatic carriers and a group of chronic HBV sufferers comparing 2 detection assays.

\section{Materials and Methods}

Serum samples were collected from 28 chronic HBV patients and 22 chronic asymptomatic carriers from the Digestive Service at the Basurto University Hospital in Basque Country in the north of Spain. All participants in this study gave their consent and were tested for liver profile (serum albumin, alanine aminotransferase, alkaline phosphatase and bilirubin levels).

HBV DNA was isolated from serum samples using the commercially available QUIamp DNA Blood minikit (Qiagen, Hilden, Germany). INNO-LIPA genotyping assay was carried out by nested PCR assay using primers from the HBV P gene region as described previously [5]. Amplification products were hybridized using a line probe assay designed to identify $\mathrm{HBV}$ genotypes $\mathrm{A}-\mathrm{H}$ by the detection of type-specific sequences in the HBV polymerase gene domain B-C (INNO-LIPA HBV genotyping assay, Innogenetics, Belgium) according to the manufacturer's instructions. For resistance mutations INNO-LIPA DR v2 and INNO-LIPA DR v3 prototype (Innogenetics) were performed.

TRUGENETM HBV genotyping kit (Siemens Healthcare Diagnostics, USA) was used simultaneously for HBV genotype and drug-resistance mutations.

The presence of mixed genotype infection and indeterminate or discordant results were verified by sequencing. The PCR product was purified with QUIAquick PCR purification kit (Qiagen, Hilden, Germany) and sequenced using the BigDye Terminator Cycle sequencing kit on an ABI Prism 3130 Genetic Analyzer (Applied Biosystems, USA).

INNO-LIPA and TRUGENE Assays for HBV Detection
Table 1. Demographic, serological and risk data of the subjects included in the study

\begin{tabular}{lcc}
\hline & $\begin{array}{l}\text { Chronic } \mathrm{HBV}^{\mathrm{a}} \\
(\mathrm{n}=28)\end{array}$ & $\begin{array}{l}\text { Carriers }^{\mathrm{b}} \\
(\mathrm{n}=22)\end{array}$ \\
\hline $\begin{array}{l}\text { Men, n (\%) } \\
\text { Mean median age, years (range) }\end{array}$ & $\begin{array}{l}42.39(67.8) \\
\text { HBeAg positive, n (\%) }\end{array}$ & $14(63.6)$ \\
Country of origin, (\%): & $9(32.1)$ & $41(18-69)$ \\
$\quad$ China & $3(10.7)$ & 0 \\
Colombia & $1(3.5)$ & 0 \\
Sub-Saharan area & $2(7.1)$ & $3(13.6)$ \\
Pakistan & $1(3.5)$ & 0 \\
$\quad$ Europe & $21(75)$ & $19(86.4)$ \\
Risk factors, n (\%): & $7(25)$ & $2(9.1)$ \\
$\quad$ Sexual & $3(10.7)$ & $3(13.6)$ \\
Transfusion & $1(3.5)$ & $6(27.2)$ \\
Maternal transmission & $1(3.5)$ & $1(4.5)$ \\
Interfamilial & 0 & $1(4.5)$ \\
Tattoos & $16(57.1)$ & $9(40.9)$ \\
$\quad$ Unknown & &
\end{tabular}

a Patients with chronic HBV infection.

b Chronic asymptomatic carriers.

Table 2. HBV genotype analysis methods comparison

\begin{tabular}{lccll}
\hline Genotype & \multicolumn{2}{l}{ Number of samples } & $\begin{array}{l}\text { INNO-LIPA } \\
\text { concordant } \\
\text { results, \% }\end{array}$ & $\begin{array}{l}\text { TRUGENE } \\
\text { concordant } \\
\text { results, \% }\end{array}$ \\
\hline chronic HBV & carriers & & \\
$\mathrm{A}$ & 7 & 6 & 100 & 100 \\
$\mathrm{~B}$ & 1 & 0 & 100 & 100 \\
$\mathrm{C}$ & 2 & 0 & 100 & 100 \\
$\mathrm{D}$ & 13 & 10 & 95.6 & 100 \\
$\mathrm{E}$ & 2 & 2 & 100 & 100 \\
$\mathrm{~F}$ & 2 & 0 & 100 & 100 \\
$\mathrm{~A} / \mathrm{F}$ & 1 & 0 & 100 & 100 \\
$\mathrm{D} / \mathrm{H}$ & 0 & 2 & 100 & 100 \\
$\mathrm{E} / \mathrm{F}$ & 0 & 1 & 100 & 100 \\
A/D & 0 & 1 & 100 & 100 \\
\hline Total & 28 & 22 & 99.56 & 100 \\
\hline
\end{tabular}

a Patients with chronic HBV infection.

${ }^{\mathrm{b}}$ Chronic asymptomatic carriers.

\section{Results}

A total of 50 patients were included in the study: 28 in the chronic HBV patient group and 22 in the chronic asymptomatic carrier group. Demographic, serological and risk data are shown in table 1.

All serum samples were analyzed by using the INNOLIPA and TRUGENE ${ }^{\mathrm{TM}}$ HBV genotyping assays (table 2). 
Results were in agreement in 49 cases (98\%) but there was an indeterminate result using INNO-LIPA assay that was identified as genotype D using the TRUGENE assay and confirmed by sequencing PCR product. In this case, the sensitivity was $99.56 \%$ in INNO-LIPA and $100 \%$ in TRUGENE. Moreover, there were no false-positive results so the specificity was $100 \%$ in both assays. Both detection assays were able to detect mixed genotypes (10\%). In our study population, genotype D was dominant $(46 \%)$ followed by genotype A (26\%). Patients infected with genotypes $\mathrm{B}$ and $\mathrm{C}$ were from China, those with genotype $\mathrm{E}$ from the sub-Saharan area and those with genotype A/F from Colombia.

For the detection of drug-resistance mutations, we treated patients with chronic HBV infection with lamivudine, adefovir and/or entecavir (data not shown). In 28 patients, 7 presented different mutations according to treatment with nucleoside/tide analogs (table 3). The INNO-LIPA assay was able to detect 15 of 16 (93.75\%) mutations and TRUGENE detected all of them. The discordant result was sequenced and the result was similar to TRUGENE (S202G entecavir-resistant mutation). In the group of chronic asymptomatic carriers, only 1 patient presented a mutation that was only detected by TRUGENE and confirmed by sequencing (V214A lamivudine-resistant mutation). The specificity in both assays was $100 \%$ and the overall sensitivity was $93.75 \%$ in the INNO-LIPA assay and $100 \%$ in TRUGENE assay.

Analyzing the risk factors for our population, most of our patients were infected by an unknown mechanism $(25 / 50,50 \%)$ followed by sexual $(18 \%)$ or maternal transmission (14\%), transfusion (12\%), interfamilial factors (4\%) and tattoos (2\%).

Characteristics of patients with chronic HBV are shown in table 4.

\section{Discussion}

This study describes the comparison of two HBV genotyping and drug-resistance mutations assays (INNOLIPA and TRUGENE). The genetic variability of this virus is greater than any other DNA virus and its sequence has different types of variability [13]. The HBV genotype or local strain is the first type of variability and is stably transmitted within the host population. INNO-LIPA is a line probe assay able to detect the main HBV genotypes and different drug-resistance mutations using 2 different kits for this purpose. TRUGENE, however, uses direct se-
Table 3. HBV drug-resistance mutations analysis methods comparison

\begin{tabular}{|c|c|c|c|c|}
\hline \multirow{2}{*}{$\begin{array}{l}\text { Drug-mutations } \\
\text { resistance }\end{array}$} & \multicolumn{2}{|c|}{ Number of samples } & \multirow{2}{*}{$\begin{array}{l}\text { INNO-LIPA } \\
\text { concordant } \\
\text { results, \% }\end{array}$} & \multirow{2}{*}{$\begin{array}{l}\text { TRUGENE } \\
\text { concordant } \\
\text { results, \% }\end{array}$} \\
\hline & chronic $\mathrm{HBV}^{\mathrm{a}}$ & carriers $^{\mathrm{b}}$ & & \\
\hline L180M & 4 & 0 & 100 & 100 \\
\hline A181V & 2 & 0 & 100 & 100 \\
\hline T184A & 1 & 0 & 100 & 100 \\
\hline S202G & 2 & 0 & 50 & 100 \\
\hline M204I & 2 & 0 & 100 & 100 \\
\hline M204V & 1 & 0 & 100 & 100 \\
\hline M204V/I & 1 & 0 & 100 & 100 \\
\hline V214A & 0 & 1 & 0 & 100 \\
\hline $\mathrm{N} 236 \mathrm{~T}$ & 3 & 0 & 100 & 100 \\
\hline Total & 16 & 1 & 93.75 & 100 \\
\hline
\end{tabular}

Table 4. Characteristics of patients with chronic HBV

\begin{tabular}{lll}
\hline & $\begin{array}{l}\text { HBeAg- } \\
\text { positive } \\
(\mathrm{n}=9)\end{array}$ & $\begin{array}{l}\text { HBeAg- } \\
\text { negative } \\
(\mathrm{n}=19)\end{array}$ \\
\hline Men, n (\%) & $6(66.6)$ & $13(68.4)$ \\
Mean median age, years (range) & $41.22(14-58)$ & $42.94(20-63)$ \\
HBV-DNA level (log copies/ml) & 5.74 & 4.92 \\
HBV genotype: & & \\
Genotype A & 3 & 4 \\
Genotype B & 0 & 1 \\
Genotype C & 1 & 1 \\
Genotype D & 5 & 8 \\
Genotype E & 0 & 2 \\
Genotype F & 0 & 2 \\
Genotype A/F & 0 & 1 \\
Fibrosis & 2 & 4 \\
\hline
\end{tabular}

quence analysis, detecting the HBV genotype and primary and secondary mutations based in stored reference sequences at the same time.

Genotypes may result from evolutionary drift of the viral genome, from recombination or as a consequence of a long-term adaptation of the virus to genetic determinants of specific host populations. HBV genotyping is an important tool within the diagnostic clinical laboratory. There are many published data showing differences between the clinical response of the infection and implicated genotypes. In this way, patients infected with A or B genotypes usually have a better clinical response than patients infected with C or D genotypes [14]. Moreover, 
long-term therapy using nucleoside/tide analogs is also associated with selection of HBV polymerase mutants and the emergence of resistance and it could be a prognostic marker of viral breakthrough [15].

Several technologies are available for identification of HBV genotypes and drug-resistance mutations, but these techniques must be easy and rapid to perform in order to apply them in the laboratory. In our study, both assays were simple and adequate for routine use in a clinical laboratory. Genotype coinfection has been considered a rare event, probably due to suppression of the replication of the second strain, or being hidden by the very high virus load of the first strain, but this information may be valuable in guiding treatment regimens [16-18]. Furthermore, genotype coinfection could raise the possibility of recombination between genotypes. In this study group, there were 5 patients with dual coinfection.

Using INNO-LIPA and TRUGENE assays, we detected different genotypes. Genotypes D and A were the most prevalent (46 and $26 \%$ ) but others such as E (8\%), C (4\%), $\mathrm{F}(4 \%)$ and B (2\%) were also detected principally in immigrant populations, showing the circulating of unusual HBV genotypes in our population. These findings are in accordance with the specific geographical distribution of HBV genotypes $[3,19,20]$, but the presence of unusual HBV genotypes in our area should be monitored in the future for differences in epidemiology or response to antiviral therapy.

Both assays were also able to detect drug-resistance mutations. These mutations could be detected in patients treated with nucleoside/tide analogs but also in an asymptomatic carrier, indicating that patients without treatment would be examined for drug-resistance mutations stage. Moreover, in our study, TRUGENE detected 1 more mutation than INNO-LIPA (V214A) and can also detect secondary mutations such as Q215S that some studies reveal can occur in chronic HBV patients even without exogenous selection pressures [21].

In general, both assays presented an excellent specificity, but TRUGENE had slightly better sensitivity in both methods than INNO-LIPA (100 vs. $99.56 \%$ on genotype detection and 100 vs. $93.75 \%$ in detection of drug-resistance mutations). Furthermore, the TRUGENE assay presented the advantage that the same sample could be used in order to detect the genotype and the drug-resistance mutations, while in the INNO-LIPA assay it was necessary to conduct two different detections. So less time was needed for the TRUGENE assay in the routine diagnostic laboratory; this assay does have the disadvantage, however, of having to prepare an acrylamide gel to carry out the sequencing procedure, which is more laborious than a line probe assay.

Different risk factors of $\mathrm{HBV}$ acquisition have been described [22]. In our study, unknown transmission was the most prevalent, followed by sexual and maternal transmission. Some studies indicate that genotype A is more efficiently transmitted sexually than genotype D, but that genotype $\mathrm{D}$ is more prevalent in intravenous drug users $[23,24]$. We could not confirm this report.

In conclusion, INNO-LIPA and TRUGENE are 2 assays that are easy and suitable for detecting HBV genotypes and drug-resistance mutations and are appropriate for routine use in a laboratory. It is clear that HBV genotyping and detection of mutations have a useful place within the diagnostic repertoire of the clinical laboratory.

\section{Acknowledgments}

This study was funded and supported by the University of Basque Country (EHU06/13).

\section{References}

1 Custer B, Sullivan SD, Hazlet TK, Iloeje U, Veenstra DL, Kowdley KV: Global epidemiology of hepatitis B virus. J Clin Gastroenterol 2004;38(suppl 10):S158-S168.

2 Beasley RP: Hepatitis B virus: the major etiology of hepatocellular carcinoma. Cancer 1988; 61:1942-1956.

> Norder H, Couroucé AM, Coursaget P, Echevarria JM, Lee SD, Mushahwar IK, Robertson $\mathrm{BH}$, et al: Genetic diversity of hepatitis B virus strains derived worldwide: genotypes, subgenotypes, and $\mathrm{HBsAg}$ subtypes. Intervirology 2004;47:289-309.
4 Zoulim F, Perrillo R: Hepatitis B: Reflections on the current approach to antiviral therapy. J Hepatol 2008;48:S2-S19.

-5 Stuyver L, Caroline VG, Gendt SD, Van Reybroeck G, Zoulim F, Lerouz-Roels G, Rossau $\mathrm{R}$ : Line probe assay for monitoring drug resistance in hepatitis B virus-infected patients during antiviral therapy. J Clin Microbiol 2000;38:702-707.
6 Chattopadhyay S, Das BC, Hussain Z, Kar P: Hepatitis B virus genotypes in acute and fulminant hepatitis patients from north India using two different molecular genotyping approaches. Hepatol Res 2006;35:79-82.

7 Liu WC, Mizokami M, Buti M, Lindh M, Young KC, Sun KT, Chi YC, et al: Simultaneous quantification and genotyping of hepatitis B virus for genotypes A to $G$ by real-time PCR and two-step melting curve analysis. J Clin Microbiol 2006;44:44914497.
INNO-LIPA and TRUGENE Assays for HBV Detection 
8 Piñeiro-Leone FG, Pezzano SC, Torres C, Rodriguez CE, Garay E, Fainboim HA, Remondegui $C$, et al: Hepatitis $B$ virus genetic diversity in Argentina: dissimilar genotype distribution in two different regions; description of hepatitis B surface antigen variants. J Clin Virol 2008;42:381-388.

$>9$ Vernet G, Tran N: The DNA-Chip technology as a new molecular tool for the detection of HBV mutants. JClin Virol 2005;34(suppl 1):S49-S53.

-10 Ding L, Rui C, Zhansheng J, Xiangling W, Ping L, Zhen Y, Yanhai G, et al: Detection of hepatitis $\mathrm{B}$ virus genotypes A to D by the fluorescence polarization assay based on asymmetric PCR. J Virol Methods 2010;168:31-37.

-11 Pawlotsky JM, Dusheiko G, Hatzakis A, Lau D, Lau G, Liang TJ, Locarnini S, et al: Virologic monitoring of hepatitis $\mathrm{B}$ virus therapy in clinical trials and practice: recommendations for a standardized approach. Gastroenterology 2008;134:405-415.

12 Deng L, Tang H: Hepatitis B virus drug resistance to current nucleos(t)ide analogs: mechanisms and mutation sites. Hepatol Res 2011; 41:1017-1024.
13 Günther S: Genetic variation in HBV infection: genotypes and mutants. J Clin Virol 2006;36:S3-S11.

14 Kao JH, Chen PJ, Lai MY, Chen DS: Genotypes and clinical phenotypes of hepatitis $\mathrm{B}$ virus in patients with chronic hepatitis $B$ virus infection. J Clin Microbiol 2002;40:12071209.

15 Locarnini S, Mason WS: Cellular and virological mechanisms of $\mathrm{HBV}$ drug resistance. J Hepatol 2006;42:121-129.

16 Pas SD, Tran N, de Man RA, BurghoornMaas C, Vernet G, Niesters HGM: Comparison of reverse hybridization, microarray, and sequence analysis for genotyping hepatitis B virus. J Clin Microbiol 2008;46:1268-1273.

17 Hannoun C, Krogsgaard K, Horal P, Lindh M: Genotype mixtures of hepatitis B virus in patients treated with interferon. J Infect Dis 2002;15:752-759.

18 Ali MM, Hasan F, Ahmad S, Al-Nakib W: Comparative evaluation of INNO-LIPA HBV assay, direct DNA sequencing and subtractive PCR-RFLP for genotyping of clinical HBV isolates. Virology J 2010;7:111

19 Vieth S, Manegold C, Drosten C, Nippraschk T, Günther S: Sequence and phylogenetic analysis of hepatitis B virus genotype $\mathrm{G}$ isolated in Germany. Virus Genes 2002;24:153156.
20 Deterding K, Constantinescu I, Nedelcu FD, Gervain J, Nemecek V, Srtunecky O, Vince A, et al: Prevalence of HBV genotypes in Central and Eastern Europe. J Med Virol 2008;80: 1707-1711.

21 Amini-Bavil-Olyaee S, Herbers U, Mohebbi SR, Sabahi F, Zali MR, Luedde T, Trautwein $\mathrm{C}$ et al: Prevalence, viral replication efficiency and antiviral drug susceptibility of rtQ215 polymerase mutations within the hepatitis $\mathrm{B}$ virus genome. J Hepatol 2009;51:647-654.

22 Dehesa-Violante M, Núñez-Nateras R: Epidemiology of hepatitis virus B and C. Arch Med Res 2007;38:606-611.

-23 Zehender G, De Maddalena C, Giambelli C, Milazzo L, Schiavini M, Bruno R, Tanzi E, et al: Different evolutionary rates and epidemic growth of hepatitis $\mathrm{B}$ virus genotypes $\mathrm{A}$ and D. Virology 2008;380:84-90.

-24 Tanaka Y, Hasegawa I, Kato T, Orito E, Hirashima N, Acharya SK, Gish RG, et al: A case-control study for differences among hepatitis $B$ virus infections of genotypes A (subtypes Aa and Ae) and D. Hepatology 2004;40: 747-755. 